\title{
«Pues reprimamos / esta fiera condición»: márgenes para la rebeldía en la tragedia del Siglo de Oro'
}

\section{«Pues reprimamos / esta fiera condición»: Margins for Rebellion in the Golden Age Tragedy}

\section{María Rosa Álvarez Sellers}

Universitat de València

ESPAÑA

Maria.R.Alvarez@uv.es

[Hipogrifo, (issn: 2328-1308), 6.1, 2018, pp. 229-245]

Recibido: 28-02-2017 / Aceptado: 21-04-2017

DOI: http://dx.doi.org/10.13035/H.2018.06.01.18

Resumen. La tragedia surge en el entorno griego pero evoluciona hacia parámetros temáticos diferentes acordes con el universo simbólico de la época que la acoge, aunque su arquitectura formal permanezca pese a variar los acentos de sus lecturas. Así, en el Siglo de Oro, la fatalidad será sustituida por la responsabilidad, que ya no recae en los dioses sino en el personaje. Mas dotando al héroe de libre albedrío, convirtiéndolo en artífice de su destino y haciendo de la divinidad un testigo de las faltas y no un agente de las mismas, la tragedia barroca abrió un margen para la rebeldía que encontró distintos resquicios por los que colarse. Analizaremos esos márgenes por los que transitan las conductas subversivas de personajes relegados por su origen ignoto como Segismundo y Rosaura en La vida es sueño, pero también el recorrido inverso, el de aquellos que se rebelarán desde una posición privilegiada que choca con el deseo, instalado en el peligroso filo entre el pensamiento y la actuación, y pagarán un alto precio por transgredir las normas sociales, como Federico y Casandra en El castigo sin venganza, o las esposas de las tragedias de honra calderonianas, confiadas en que «no yerra quien piensa», para terminar con un inesperado margen para la rebeldía porque procede de un

1. Este trabajo se enmarca dentro del Proyecto I+D de Excelencia del Ministerio de Economía y Competitividad, ref. FFI2014-58570-P. 
personaje insospechado: el gracioso que, contraviniendo y desafiando su esencia cómica, acabará por implicarse en la tragedia.

Palabras clave. Tragedia; Siglo de Oro; rebeldes; marginados; gracioso; La vida es sueño; El castigo sin venganza; El médico de su honra; La cisma de Inglaterra; El caballero de Olmedo.

Abstract. The tragedy arises in a Greek setting but evolves towards different thematic parameters according to the symbolic universe of the time that welcomes it, although its formal architecture remains in spite of the varying nuances of its readings. Thus, in the Golden Age, fatality will be replaced by responsibility, which no longer rests with the gods but with the characters. By endowing the hero with freewill, making him the creator of his destiny and making divinity a witness of faults and not an agent of them, the Baroque tragedy opened a space for rebellion that found different gaps through which it could enter.

We will analyse those margins in which are evident the subversive behaviours of characters relegated by their unknown origin, such as Segismundo and Rosaura, in La vida es sueño, but also the reverse route, in which those who rebel from a privileged position that clashes with desire, are installed on the dangerous edge between thinking and acting, and they will pay a heavy price for transgressing social norms, such as Federico and Casandra in El castigo sin venganza, or the wives of Calderonian honour tragedies, confident that «no yerra quien piensa». It will end with an unexpected margin for rebellion because this rebellion comes from an unsuspected character: the gracioso who, directly contravening and challenging his comic essence, will eventually become involved in the tragedy.

Keywords. Tragedy; Golden Age; Rebels; Marginalized; gracioso La vida es sueño; El castigo sin venganza; El médico de su honra; La cisma de Inglaterra; El caballero de Olmedo.

\author{
¿No nacieron los demás? \\ Pues si los demás nacieron, \\ ¿qué privilegios tuvieron \\ que yo no gocé jamás? \\ Segismundo, La vida es sueño \\ (I, vv. 119-122)
}

La tragedia es el género más antiguo, pero también uno de los de mayor capacidad proteica, de adaptación a nuevos tiempos y circunstancias. Nace en el entorno griego para tratar de dar respuesta al enfrentamiento del hombre con fuerzas superiores que escapan a su control y dirigen sus actuaciones por caminos trazados previamente que no es posible desviar. Pero el conflicto es un motivo universal característico del género trágico y susceptible de articularse y resolverse desde planteamientos y desenlaces acordes con los cambios de mentalidad que la sociedad ha ido experimentando. Por eso no quedó prisionero del pensamiento pagano, y cuando un solo Dios tome el relevo de los dioses grecolatinos, la fatali- 
dad será sustituida por la responsabilidad, que ya no recae en las divinidades sino en el personaje.

Y este cambio de papeles dio paso a una tragedia diferente, que traslada el sufrimiento desde la ignorancia hasta el conocimiento. «Cada cual se fabrica su destino. / No tiene allí fortuna alguna parte», dirá Cipión (I, vv. 157-158)² en La Numancia de Cervantes. Esa será la clave de la tragedia española renacentista y barroca, que tampoco responde a un modelo único. Si los dramaturgos del XVI se proponen recuperar la tragedia, en parte por el prestigio del género, en parte por ser el más adecuado para denunciar lacras sociales y morales, no bastará su empeño para lograr el éxito. La tragedia del XVII deja atrás la retórica y la truculencia y apuesta por la palabra y el montaje, potenciando la reflexión en lugar del espectáculo ${ }^{3}$. Pero se parte en ambos casos de una creencia común: la inevitable e imperiosa necesidad de cambiar con los tiempos.

... la edad se ha puesto de por medio, rompiendo los preceptos por él puestos, y quitándome un acto, que solía estar en cinco siempre dividida. Me han quitado también aquellos coros que andaban de por medio entre mis scenas, y a la verdad no siento ya esta falta por no cobrar el nombre de prolija ${ }^{4}$.

O los conocidos versos de Lope de Vega en su Arte nuevo:

... y, cuando he de escribir una comedia, encierro los preceptos con seis llaves; saco a Terencio y Plauto de mi estudio, para que no me den voces, que suele dar gritos la verdad en libros mudos, y escribo por el arte que inventaron los que el vulgar aplauso pretendieron, porque, como las paga el vulgo, es justo hablarle en necio para darle gusto 5 .

2. Cervantes, La destruición de Numancia, ed. Hermenegildo.

3. En 1997 publiqué mi tesis doctoral, Análisis y evolución de la tragedia española en el Siglo de Oro: la tragedia amorosa. Posteriormente, los estudios sobre el género han dado lugar a un largo debate y una prolija bibliografía. Pese a tenerlos en cuenta, por razones de espacio solo podré citar algunos a lo largo de estas páginas.

4. Lupercio Leonardo de Argensola, loa a su tragedia Alejandra. Citado por Hermenegildo, 1985, p. 45. Couderc, 2012, p. 75, se pregunta si existe «une tragédie nouvelle»: «En Espagne, il est donc devenu possible d'abandonner la conception traditionnelle de la tragédie au profit d'une conception nouvelle, légitimée par Aristote» (p. 80). Iglesias Feijoo, 2009 y 2012, también emplea la terminología «tragedia nueva». 5. Lope de Vega, Arte nuevo de hacer comedias, ed. Pedraza y Conde, vv. 40-48. Couderc, 2012, p. 81, destaca la atención al receptor: «Plus que l'application mécanique de principes théoriques, il peut être utile de chercher une correspondance entre un art dramatique qui évolue et un traité redécouvert où 
Ahora bien, aunque el trasfondo metafísico de la tragedia griega haya desaparecido, la arquitectura formal que la sostenía permaneció intacta, pues no había perdido su funcionalidad aunque variasen los acentos de sus lecturas. Así, el conflicto -agon-, el error -hamartia-, la persistencia en el mismo - hybris-, el sufrimiento - pathos - y la catarsis se mantienen, a veces completados por la anagnórisis, pues no todos los personajes toman conciencia de sus yerros, como sucede con los maridos deshonrados, que no creen equivocarse al ajusticiar en el tribunal del honor a una esposa que suele ser inocente.

Pero dotando al héroe de libre albedrío, convirtiéndolo en artífice de su destino y haciendo de la divinidad un testigo de las faltas y no un agente de las mismas, la tragedia barroca abrió un margen para la rebeldía que encontró distintos resquicios por los que colarse. Si el conflicto trágico nace de la oposición y el enfrentamiento, podríamos decir que este se articula en torno a dos líneas maestras: individuo / sociedad y libertad / destino, ejemplificadas, respectivamente, en las calderonianas El médico de su honra y La vida es sueño6.

No se trata de contextos separados por un muro infranqueable, y prueba de ello es La vida es sueño, que aúna ambas directrices. Si Segismundo considera que «el delito mayor / del hombre es haber nacido» (I, vv. 11-12) ${ }^{7}$, Rosaura plantea el grave problema de la honra desde la perspectiva de la mujer que ha sido abandonada y, en consecuencia, se enfrenta al rechazo y a la marginación, cuya única salida airosa es ocultar lo sucedido mediante el aislamiento ${ }^{8}$. Sin embargo, no se resigna a asumir un destino impuesto por las normas sociales y decide ir en pos de su ofensor y labrar su propia suerte. Para ello debe adoptar una identidad ficticia hasta que llegue el momento adecuado para revelar su propósito, y como única seña lleva consigo una espada, atributo masculino con el que quizá consiga la ayuda de algún poderoso, ya que «encierra misterios grandes; / pues sólo fiado en ella / vengo a Polonia a vengarme / de un agravio» (I, vv. 374-377). Rosaura ha sido abandonada por dos hombres, su padre y su amado, y debe encontrar a ambos y obligarles a cumplir con sus obligaciones para escapar al sino de marginación que la aguarda, pues es «mercader sin trato / deshonrada una mujer» (II, vv. 1022-1023), como bien sabe Tamar ${ }^{9}$.

donc on ne peut qu'apprécier en Espagne l'orientation pragmatique et la constante préoccupation pour le public qui s'y exprime».

6. Ver Álvarez Sellers, 1995, pp. 41-42. En este trabajo, ganador del Premio Nacional de Ensayo «Becerro de Bengoa» (1993, Diputación Foral de Álava), argumenté sobre la consideración de La vida es sueño como tragedia. Como era de esperar tratándose de una obra tan compleja como relevante, el debate sigue abierto. Si Vitse, 1997, p. 62, la calificaba de «la mejor vía de acceso a la comprensión de la tragedia calderoniana», para Zugasti (2015) estamos ante una «comedia palatina seria».

7. Calderón, La vida es sueño, ed. Rodríguez Cuadros.

8. El punto de vista femenino es el que en la tragedia no merece ser considerado, pues la mera sospecha es suficiente para que el esposo decida la triste suerte de una mujer a la que hasta el momento de surgir la duda decía amar sin reservas, como don Gutierre a Mencía: «No dejo de ser amante / yo, mi bien, por ser marido» (El médico de su honra, ed. Pérez Magallón, II, vv. 163-164).

9. Calderón, Los cabellos de Absalón, ed. Rodríguez Cuadros. Tamar es violada por su hermanastro Amón, que al día siguiente la desprecia: «iSal fuera, que eres horror / de mi vida y su escarmiento!» (II, vV. 
Rosaura cae del caballo e irrumpe con violencia en un espacio que traduce su propia confusión, donde es difícil distinguir los contornos, donde «si la vista no padece engaños / que hace la fantasía» (I, vv. 50-51), a la luz del crepúsculo, cree ver «una prisión obscura / que es de un vivo cadáver sepultura; / y porque más me asombre, / en el traje de fiera yace un hombre / de prisiones cargado,» (I, Vv. 93-97) que también se queja de su fortuna ${ }^{10}$.

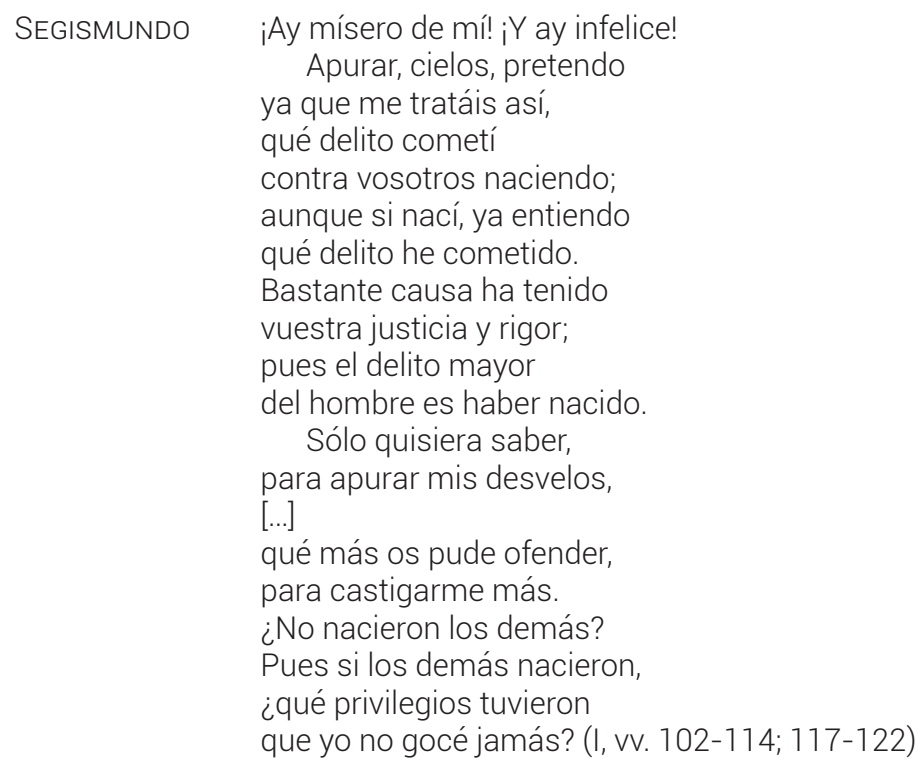

Entre perplejo y desesperado, Segismundo pronuncia estos versos altamente subversivos que apuntan directamente a la desigualdad y la injusticia: si nacer es un delito cometido por todos, cómo es posible sentirse inferior incluso a criaturas irracionales, pues aves, brutos, peces y arroyos gozan de una libertad que él, con «más alma», «mejor instinto», «más albedrío» y «más vida» tiene vedada sin que alcance a explicarse el motivo. Esa percepción clara del agravio le lleva a canalizar su rebeldía a través de la furia:

En llegando a esta pasión un volcán, un Etna hecho, quisiera sacar del pecho pedazos del corazón. ¿Qué ley, justicia o razón negar a los hombres sabe privilegio tan süave,

1004-1005), pero ella pide justicia a su padre, el rey David, ante la Corte. Amón es perdonado y Tamar se ve obligada a recluirse en la quinta de su hermano Absalón, que más tarde invitará a Amón a un banquete y allí le dará muerte para vengar la deshonra.

10. Para Maspoch Bueno, 1997, p. 109, este atuendo de Segismundo anticipa «su comportamiento como príncipe y héroe, puesto que con pieles de fiera se vienen vistiendo los héroes desde la antigüedad». 


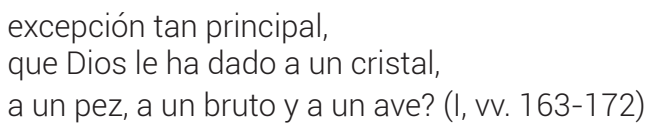

Y no da crédito a que la ley humana sea superior a la divina, privándole de una condición que Dios ha otorgado como un don natural. Con todo, no es un ignorante, pues posee un saber platónico adquirido en los libros, por eso aunque al descubrir a Rosaura su primer impulso será querer matarla «porque no sepas que sé, / que sabes flaquezas mías» (I, vv. 181-182), de inmediato pasará a la admiración, «Tu voz pudo enternecerme, / tu presencia suspenderme, / y tu respeto turbarme. / ¿Quién eres?» (I, vv. 190-193) e incluso a los requiebros galantes:

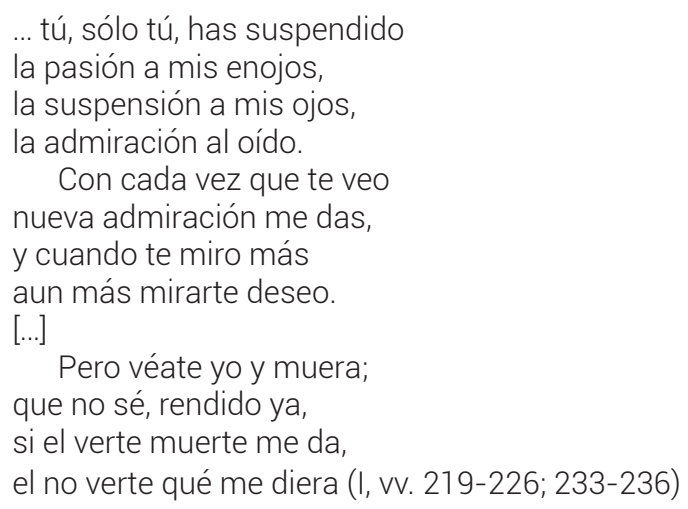

La elocuente Rosaura también se ha quedado sin palabras:

ROSAURA Con asombro de mirarte, con admiración de oírte, ni sé qué pueda decirte, ni qué pueda preguntarte (I, vv. 243-246)

Pero ese hiato en el tiempo es bruscamente interrumpido por el guardián del cautivo, que detiene al intruso, y cuando Segismundo amenaza con suicidarse, única arma de la que dispone, Clotaldo le recuerda lo inútil de su rebeldía:

Clotaldo Si sabes que tus desdichas, Segismundo, son tan grandes, que antes de nacer moriste por ley del cielo; si sabes que aquestas prisiones son de tus furias arrogantes un freno que las detenga y una rienda que las pare, ¿por qué blasonas? (I, vv. 319-327) 
Zarandeado por las circunstancias, preso de decisiones ajenas que gobiernan su vida, Segismundo ha sido marginado por su padre, el rey Basilio, no por haber nacido, como él cree, sino por haberlo hecho bajo el signo de un horóscopo adverso enunciado por un rey que se precia de sabio ${ }^{11}$ mirando en sus tablas «presentes las novedades / de los venideros siglos» (I, vv. 620-621), y que encerrando a su hijo cree estar obrando de forma prudente. Pero se acerca el fin de su reinado y urge dejar un heredero, y entonces considera «el ver cuánto yerro ha sido / dar crédito fácilmente / a los sucesos previstos;» (I, vv. 781-783) e introduce una desviación en su plan inicial: traerá narcotizado a su hijo a la Corte y, si al despertar actúa como corresponde a un príncipe, le permitirá reinar; de lo contrario, regresará a la torre creyendo que todo ha sido un sueño.

La experiencia confirma los recelos de Basilio y lo acertado de su actuación primera. Ignorante de las normas elementales de convivencia, abrumado por un poder tan repentino como absoluto, Segismundo es un volcán que proyecta rabia y violencia contra Rosaura -a la que ahora encuentra vestida de dama-, contra Astolfo, contra un soldado, contra Clotaldo y contra el propio rey, al que califica de «Tirano de mi albedrío» (II, v. 1504):

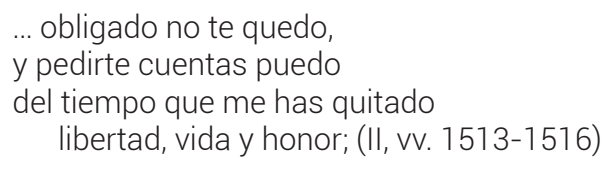

Poco antes había formulado un enunciado tan subversivo como el que pronunció en la torre, negando la obediencia ciega al rey si este no sabe mandar lo justo, palabras que solo puede decir un marginado que desconoce el código del honor y por eso mismo se atreve a ponerlo en entredicho:

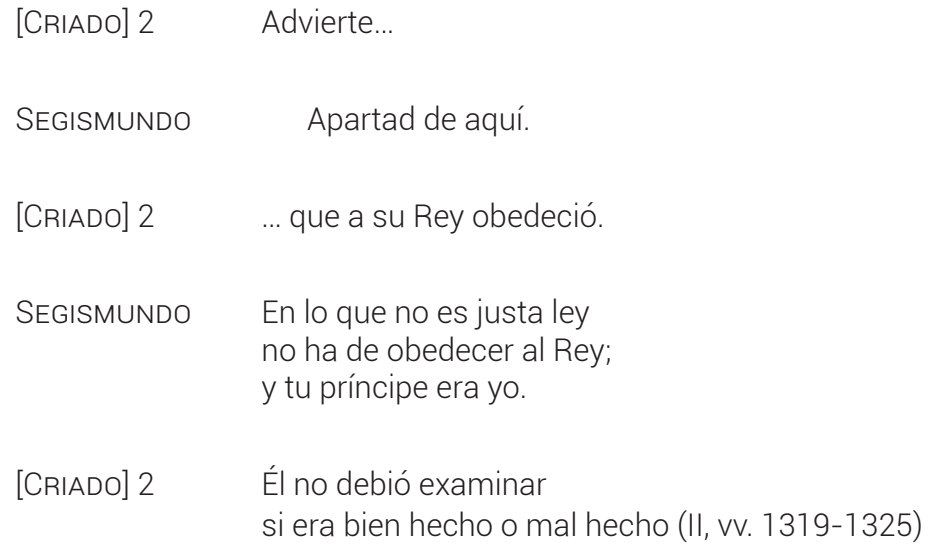


Por segunda vez Segismundo, noble sin saberlo, sin haber sido educado como tal, se rebela contra la injusticia moral, que lo ha convertido en fiera, y la social, que lo ha privado de su lugar en el mundo, un lugar privilegiado que le correspondía por derecho de nacimiento ${ }^{12}$, por aquello que hasta hace poco consideraba el mayor delito, y vuelve a manifestar su rebeldía mediante la violencia, fruto de la incultura y el rencor. Por esa actuación instintiva carente de filtro social pagará el precio de volver a su encierro, pero ya nada será como antes. Si en un principio su planteamiento rebelde procedía de la incomprensión y la perplejidad, ahora ha aprendido que los actos tienen consecuencias cuando afectan a la convivencia, y se aferra a su recuerdo de Rosaura, porque aunque quieran hacerle creer que todo fue soñado, ese sentimiento que permanece inalterable, vaya ella vestida de hombre o de mujer, se revela como el «cogito ergo sum» de Segismundo, como lo único cierto en un mundo sometido al permanente engaño de los sentidos:

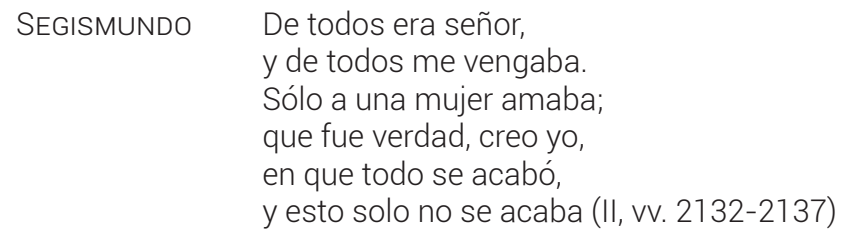

Ahora bien, esa rebeldía habría quedado recluida en las cuatro paredes de su prisión si su existencia no se hubiese hecho pública. No basta tener la razón para triunfar sobre la injusticia, y para que los acontecimientos escapen al control artificial urdido por Basilio, será necesaria la intervención de agentes externos que liberen al heredero de su involuntario encierro. Entonces será el momento de demostrar si ha aprendido de la experiencia.

La amargura del príncipe preso es un espejo de las tribulaciones de la infortunada Rosaura, ignorantes ambos de su origen, sometidos a la tiranía de la actuación egoísta de padres que han renegado de ellos y los han privado del derecho a ocupar su puesto en la sociedad de los elegidos. Seres desprovistos de centro y referente, deben asumir una identidad hermafrodita, mujer vestida de hombre o compuesto de hombre y fiera, hasta descubrir su linaje y acceder a ese honor del que carecían y que les abrirá las puertas de un mundo privilegiado del que permanecían marginados por ser hijos de padres desconocidos ${ }^{13}$. Por eso Rosaura no puede presentarse ante Astolfo y exigirle que se case con ella si antes no encuentra quien la avale, fiada en ese testigo mudo que es la espada, única seña de identidad que Clotaldo identifica al instante pero calla hasta que las circunstancias lo fuerzan a reconocer a su hija.

12. Vitse, 1997, p. 62, considera a Segismundo «la figura fundadora del optimismo dolorido del Calderón trágico. [...] una primera encarnación del héroe moderno, de un héroe aristocrático que sabe encontrar, por el "valor" de una sangre como autorregenerada, la vía hacia la gloria, el camino hacia la "fama vividora"». 13. Masposch Bueno, 1997, analiza los animales de La vida es sueño y considera que «la intriga avanza desde la condición híbrida de los personajes centrales o desde su equivalencia a las fieras hacia la conquista de esa verdadera naturaleza humana» (p. 111). 
Rosaura y Segismundo acabarán uniendo sus fuerzas para solucionar mutuamente sus problemas, desembocando su instinto y su rebeldía en el mar de la resignación y la renuncia. Conquistada su identidad, solo podrán completar su periplo de inclusión social utilizando su libre albedrío para tomar la decisión más adecuada, aunque no la más satisfactoria. Para heredar el reino, Segismundo debe borrar aquella frase que llegó a definirlo: «nada me parece justo / en siendo contra mi gusto» (II, vv. 1417-1418) ${ }^{14}$. Ahora tiene que ajustar el gusto a lo justo, por eso perdona a su padre, ofrece su mano a Estrella (III, vv. 3278-3286) y casa a Rosaura con Astolfo, pues ni su amor primero ni su reciente poder pueden borrar los errores del pasado, y un príncipe no puede desposar a una mujer deshonrada que, con su ayuda y el reconocimiento final de Clotaldo, consigue ingresar también en la sociedad que la había marginado por haber atentado contra sus preceptos.

Alejándose el uno del otro, enterrarán el sentimiento pero conservarán la vida, clave que escapa a otros personajes que realizarán el recorrido inverso, es decir, desde el privilegio social a la marginación e incluso la muerte como precio a su rebeldía. Es el caso de Federico en El castigo sin venganza (1631) de Lope de Vega, el cual alienta una pasión prohibida hacia su madrastra que no lamenta porque «no es cosa que hice» $\left(\right.$ I, v. 966) ${ }^{15}$ :

$\begin{array}{ll}\text { BATíN } & \begin{array}{l}\text { Pues mira como lo acierto: } \\ \text { que te agrada tu madrastra } \\ \text { y estás entre ti diciendo... }\end{array} \\ \text { FEDERICO } & \begin{array}{l}\text { No lo digas; es verdad, } \\ \text { pero yo, ¿qué culpa tengo, } \\ \text { pues el pensamiento es libre? (I, vv. 977-982) }\end{array}\end{array}$

Pero en la tragedia pensar la ofensa es el primer paso para cometer el delito y, aunque el pensamiento sea libre, el comportamiento no lo es cuando se vive en sociedad, como bien aprende Segismundo tras visitar la Corte. Federico y Casandra eligen desafiar las normas viviendo en secreto una relación que en el momento en que deje de ser clandestina los conducirá a la muerte, a la expulsión de ese marco social que no admite los desafíos ni las actuaciones transgresoras ${ }^{16}$.

Y la misma suerte correrán todos aquellos que crean que entre el pensar y el actuar se alza un muro que los pone a salvo de la propia imprudencia y del juicio ajeno:

14. Ver Álvarez Sellers, 2013.

15. Lope de Vega, El castigo sin venganza, ed. Kossoff.

16. Oostendorp, 1981, pp. 71-72, distingue entre tragedias cerradas -anteriores al Romanticismo- y tragedias problemáticas - posteriores al mismo-. En las primeras existe un orden, en las segundas la vida se concibe como un caos. El protagonista de la tragedia cerrada rompe o mantiene el orden superior existente en la tragedia, lo cual le causa necesaria e inevitablemente un gran dolor psíquico o físico; en las problemáticas, en cambio, el héroe anhela un orden superior. Asimismo, subraya (1983, pp. 178-179) que Calderón no se limita a «reflejar las opiniones reinantes en su época», sino que «ve con gran agudeza la grieta entre el ideal y la realidad y percibe la trágica suerte del hombre que incluso puede sucumbir a su sentido del deber engañado por las apariencias». 


CASANDRA $\quad$ Las partes del conde son
grandes, pero mayor fuera
mi desatino, si diera
puerta a tan loca pasión.
No más, necia confusión.
Salid, cielo, a la defensa,
aunque no yerra quien piensa,
porque en el mundo no hubiera
hombre con honra si fuera
ofensa pensar la ofensa.
[...]
Consentir lo imaginado,
para con Dios es error,
mas no para el deshonor;
que diferencian intentos
el ver Dios los pensamientos
y no los ver el honor (II, vv. 1572-1581; 1586-1591)

Aunque al honor no le hace falta ver, basta con que imagine que la recta línea del decoro se ha emborronado ${ }^{17}$. Las esposas de las tragedias de honra calderonianas también dan alas al pensamiento, pero en cuanto lo advierten regresan bruscamente de ese estado de enajenación transitoria para censurarse el peligro de sentir, otro paso que las acerca a una actuación inapropiada y las aleja de ese «soy quien soy» al que deben respeto absoluto si quieren conservar la vida:

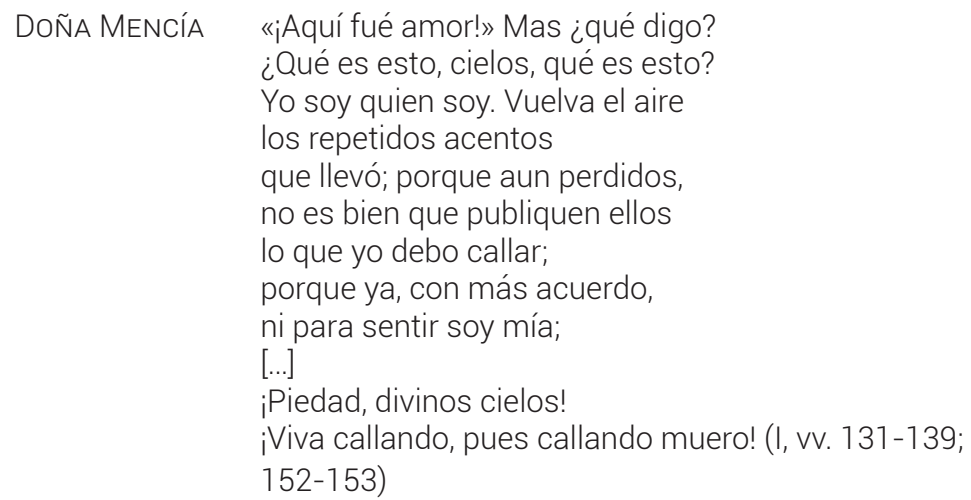

Si, en la obra de Lope, Casandra no solo peca con el pensamiento sino que hace efectiva su rebeldía entregándose «a tan loca pasión», en las tragedias de Calderón solo Leonor (A secreto agravio, secreta venganza) da un paso más consintiendo lo imaginado y citándose con su pretendiente, pero en el caso de Serafina (El pintor de su deshonra) y Mencía (El médico de su honra) la voluntad es más fuerte que el deseo, y el honor insiste en relegar el amor al único tiempo en que es posible, el

17. Losada Goya, 1997, p. 65, define cuatro aspectos bajo los que se puede presentar el honor en el teatro de Calderón: como una cualidad recibida en el nacimiento, como la pureza de sangre, como la recompensa a la virtud y como la opinión. Enlaza este último con «el honor fundado en mujer» (p. 67). 
pasado, pues no hay segundas oportunidades para el sentimiento. Sin embargo, da igual hasta donde llegue su margen de rebeldía, todas entregarán la vida en pago de la honra de sus maridos. Y tampoco el pretendiente que las coloca al borde del abismo, en el vertiginoso equilibrio de elegir entre el honor y el amor, correrá mejor suerte -excepto don Enrique en El médico de su honra por ser un personaje histórico-, pues su intento de hacer tambalear el sagrado vínculo del matrimonio traerá consigo idéntico castigo al de la dama ${ }^{18}$.

No obstante, aún queda un insospechado margen para la rebeldía, precisamente porque procede del personaje que debería permanecer fuera de la tensión, al que corresponde hacer chistes aunque la ocasión no sea la más propicia. En el caso de un personaje tipo como el gracioso podemos observar que el género marca una desviación del estereotipo, pues el gracioso de la tragedia no consigue mantenerse instalado en la comicidad y acaba implicándose en el conflicto ${ }^{19}$.

Batín, por ejemplo, es el único que conoce la gestación del proceso pasional entre Federico y Casandra, por ello se define como «desdichado por leal» (II, v. 1231). Asimismo, percibe los cambios de humor de cuantos lo rodean: «está endiablado / el conde; no sé qué tiene» (III, vv. 2792-2793), «La duquesa, pues, también / insufrible y desigual» (III, vv. 2796-2797) y «El duque, santo fingido» (II, v. 2800) «que anda buscando / algo que se le ha perdido» (III, vv. 2802-2803), frase en la que condensa con ironía la deshonra que posteriormente el Duque tratará de vengar disfrazándola de castigo; de ahí que el criado aconseje a Aurora marcharse y le pida que lo lleve con ella a Mantua:

$\begin{array}{ll}\text { AURORA } & \begin{array}{l}\text { Estoy, señor, tan turbada, } \\ \text { que no sé lo que responda. }\end{array} \\ \text { BATín } & \begin{array}{l}\text { Di que sí; que no es sin causa } \\ \text { todo lo que ves, Aurora (III, vV. 3003-3006) }\end{array}\end{array}$

O Pasquín (La cisma de Inglaterra), que utiliza su desvarío - «si no digo lo que quiero, / ¿de qué me sirve ser loco?» (I, vv. 561-562)20 - para enunciar las verdades

18. Ver Álvarez Sellers, 2016.

19. Ver Álvarez Sellers, 1997, vol. III, pp. 681-682, 890-891 y 917. Sobre la figura del gracioso y su implicación en la tragedia existe una sólida bibliografía. Ver, por ejemplo, Arellano, 2006, pp. 33-53, que habla de su paradójica conversión en «agentes trágicos» (p. 53), y vuelve sobre el tema en un artículo de 2011, p. 25: «los graciosos calderonianos asumen en las tragedias funciones sumamente serias». En la misma línea, Barone, 2012, p. 137, apunta que «la extrema connotación trágica se impone como factor predominante que inhibe la expresión de la comicidad»; Pedraza, 2013, p. 155, señala que «en muchos casos, se ve empujado a convertirse en agente trágico» y Lobato, 2013, p. 219, expone que «el gracioso es el responsable de la risa fallida en la tragedia española» (p. 219) y, como «mediador en la tragedia» (p. 220), le atribuye una «función relatora [...] en momentos nada secundarios de la intriga» (p. 220) y una «función retardadora», porque «con sus chanzas alarga la expectación ante la desgracia que está por venir de forma inexorable y de cuyo origen no es en absoluto inocente» (pp. 227-228).

20. Calderón, La cisma de Inglaterra, ed. Ruiz Ramón, quien califica esa locura de «cédula de identidad o un pase especial que le permite circular sin peligro por el laberinto palaciego y cortesano sin ser cas- 
que, en boca de un personaje serio costarían la vida, como le sucede a la reina Catalina. Así, se define como un ciego que de noche lleva una luz no para alumbrarse él sino para que los demás lo vean, y de igual modo sus palabras arrojarán destellos sobre el sentido oculto de las actuaciones del resto de personajes: «porque yo con mis locuras / soy ciego y alumbro a oscuras» (I, vv. 600-601); obtendrá de Enrique VIII el cargo de «denunciador de figuras» (II, v. 983), y le preocupará especialmente la «figura de a dos» (II, v. 1774), «figura de dos hierros, de dos filos, / de dos haces» (II, vv. 1776-1777).

Pero el gracioso de la tragedia puede llegar a tener una actuación decisiva que desmiente la propia naturaleza del personaje; poniendo incluso su vida en peligo, «decidirá arrojar su máscara de bufon» ${ }^{21}$ y llega a denunciar la sinrazón del crimen que el noble está a punto de cometer en obras tan representativas como El médico de su honra22.

\begin{tabular}{|c|c|}
\hline CoQuín & $\begin{array}{l}\text { Aunque me mates, } \\
\text { habiéndote conocido, } \\
\text { ¡oh señor!, tengo de hablarte: } \\
\text { escúchame. }\end{array}$ \\
\hline REY & $\begin{array}{l}\text { Pues, Coquín, } \\
\text { ¿de qué los extremos son? }\end{array}$ \\
\hline CoQuín & 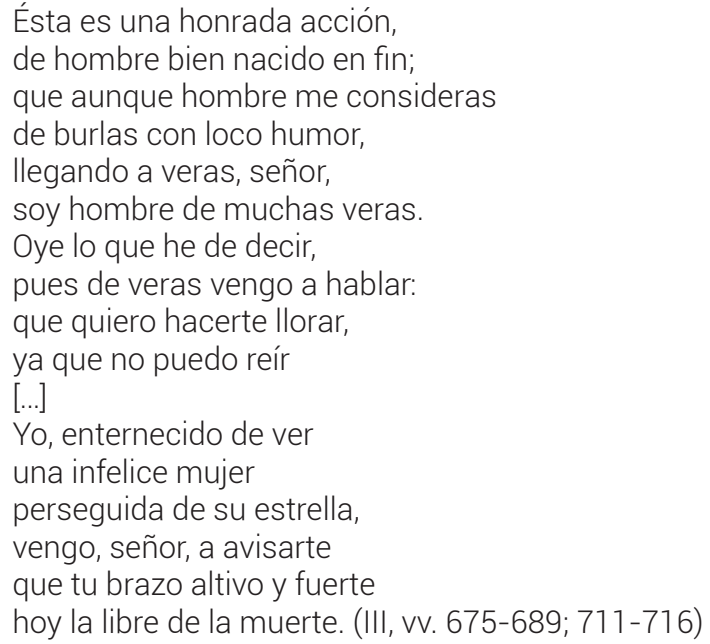 \\
\hline
\end{tabular}

tigado por las verdades que dice o las mentiras que destapa, asegurándole así completa impunidad» (2001, p. 111).

21. Ruiz Ramón, 2001, p. 110.

22. Para Barone, 2012, p. 141, el «papel risible» en esta obra revela su «impotencia contra un sistema ideológico asfixiante y la manifiesta incapacidad de los personajes para establecer una comunicación eficaz con sus interlocutores», y «sufre una fundamental evolución que determina su paradójica transformación en agente trágico» (p. 143). 
O que ya ha cometido, como en El caballero de Olmedo, pues cuando el padre de Inés consiente ante el Rey su matrimonio con don Alonso, Tello irrumpe pidiendo justicia y cuenta cómo «envuelto en su sangre veo / a don Alonso espirando» (III, vv. 2686-2687) ${ }^{23}$. Si antes fue cómplice del engaño urdido por su amo para estar cerca de su amada, ahora verbaliza el dolor de los padres del caballero y denuncia la traición de don Rodrigo y don Fernando. Es más, al ver desangrarse a su señor pide que lo maten también - «iTraidores, villanos, perros, / volved, volved a matarme» (III, vv. 2494-2495)-, mostrando un valor inusitado que no le corresponde y que el gracioso ni siquiera vislumbra en la comedia.

Así pues, solo los personajes marginados, aquellos que carecen de linaje y por tanto de honor, pueden adentrarse por la senda de la rebeldía, aunque en el caso del gracioso no pasará de la denuncia, y en el caso de los protagonistas será precisamente para abandonar de inmediato su naturaleza transgresora en cuanto alcancen su objetivo, que no es otro que formar parte de ese sistema social cuya entrada tenían vedada por su origen ignoto. Cuando el misterio de la identidad se despeje, no dudarán en renunciar a sus pasiones para abrazar unas normas que ponen coto al sentimiento pero garantizan la vida en el mundo de los elegidos, es decir, de aquellos que han asumido que el bien común está por encima de las individualidades ${ }^{24}$. Caso contrario es el de los que parten de la premisa de un bienestar social que resulta insatisfactorio porque choca con el deseo, un deseo instalado en el peligroso filo entre el pensamiento y la actuación, que solo puede sobrevivir oculto en la mente, pero que siempre acaba traspasando los límites de lo vedado y amenazando por ello la estabilidad del entramado social. Ahora bien, esa transgresión alentada por la voluntad puede hacer tambalear su arquitectura, pero nunca derribarla.

Comprobamos entonces que las subversivas palabras de Segismundo quejándose de la desigualdad entre los nacidos y de la obediencia ciega al rey aunque pueda ser tirano, se las lleva el viento en cuanto la puerta de la torre se abre por segunda vez y, ahora sí, quede para siempre cerrada a sus espaldas. Porque ese es el momento de la verdad, el momento de demostrar que ha aprendido a estar con los demás, que prefiere la convivencia a la soledad. Si los personajes que pecan de pensamiento, palabra, obra u omisión contra el código del honor están condenados a la expulsión de la sociedad privilegiada que les había dado el ser, Segismundo, que parte de la orilla opuesta, que navega en el mar de los desheredados, es el único que ha aprendido de la experiencia, que utiliza correctamente su albedrío para actuar no como se esperaba de quien era un compuesto de hombre y fiera, sino del príncipe prudente que su padre le negó ser aun antes de su nacimiento, fiado en el

23. Lope de Vega, El caballero de Olmedo, ed. Rico.

24. Sullivan, 1990, p. 40, indica que las tragedias españolas no se intitulan Hamlet, Otelo, Fedra o Andrómaca, sino El caballero de Olmedo, El médico de su honra o El castigo sin venganza, «titles that identify the protagonist in relationship to an apparently transcendent signifier or to his position or function within the social order». Citado por Greer, 2005, p. 360, que divide las tragedias españolas en varios ejes temáticos, entre ellos: «Religious and Cultural Difference» (p. 359), donde incluye El caballero de Olmedo, «Incest, Sexual and Political» (p. 360) para El castigo sin venganza y «Honor and Patriarchy, Microcosm and Macrocosm» (p. 363) para El médico de su honra. 
pronóstico de las estrellas y contrariando la libertad que Dios ha dado a sus criaturas, y con la cual Segismundo perdona a su padre, arrodillado ante él como señaló el horóscopo que, en efecto, se cumple pero literalmente, no simbólicamente como había previsto Basilio.

\begin{tabular}{ll} 
CLOTALDO & {$[\ldots]$} \\
& $\begin{array}{l}\text { Segismundo; que aun en sueños } \\
\text { no se pierde el hacer bien. } \\
\text { (Vase.) }\end{array}$ \\
SEGISMUNDO & \multicolumn{1}{l}{ Es verdad; pues reprimamos } \\
& esta fiera condición, \\
& esta furia, esta ambición \\
por si alguna vez soñamos. & Y sí haremos, pues estamos \\
& en mundo tan singular, \\
& que el vivir sólo es soñar; \\
y la experiencia me enseña \\
que el hombre que vive sueña \\
lo que es hasta despertar (II, vv. 2146-2157)
\end{tabular}

Segismundo ha aprendido la lección: hay que reprimir esa «fiera condición» para conservar vida y honor. Aunque solo hay un escollo a tan inteligente conclusión. De entre todos los rebeldes mencionados, el único que utiliza sabiamente su albedrío para resolver los conflictos sociales y morales propios y ajenos lo hace sin el convencimiento de estar despierto, inmerso todavía, a pesar de todos los grandes cambios vividos, en el desconcierto del crepúsculo en el que conoció a Rosaura, en ese confuso laberinto «donde no puede / hallar la razón el hilo» (I, vv. 976-977). Es más, cuando lo liberan, siente el vértigo del retorno, y teme estar siendo víctima de una broma pesada del destino:

Segismundo (Dentro.)

¿Otra vez (¿qué es esto, cielos?)

queréis que sueñe grandezas

que ha de deshacer el tiempo?

[...]

Pues no ha de ser, no ha de ser.

Miradme otra vez sujeto

a mi fortuna.

[...]

ya os conozco, ya os conozco

y sé que os pasa lo mesmo

con cualquiera que se duerme.

Para mí no hay fingimientos:

que, desengañado ya,

sé bien que la vida es sueño (III, vv. 2307-2309; 2318-

2320; 2338-2343) 
Finalmente, entre el nihilismo y la prudencia, acepta desempeñar su papel sin ninguna certeza, sin saber siquiera si está despierto o dormido, asumiendo, como todos los que conforman la sociedad que ahora está destinado a dirigir, la conveniencia como norma de comportamiento, y enterrando entre las brumas de un pasado tan incierto como el propio presente esa rebeldía que le llevó a exclamar «¡Ay mísero de mí! ¡Y ay infelice!» (I, v. 78), y que ha cambiado por un maquiavelismo forjado por ese ingenio que ahora a todos admira y que le permitirá conservar una fama tan inesperada como grata:

SEgISMUNDO A reinar, fortuna, vamos; no me despiertes, si duermo, y si es verdad, no me duermas. Mas, sea verdad o sueño, obrar bien es lo que importa. Si fuere verdad, por serlo; si no, por ganar amigos para cuando despertemos (III, vv. 2420-2427)

\section{BiBLIOGRAFÍA}

Álvarez Sellers, María Rosa, La tragedia española en el Siglo de Oro: «La vida es sueño» o el delito del nacimiento, Vitoria-Gasteiz, Diputación Foral de Álava, 1995.

Álvarez Sellers, María Rosa, Análisis y evolución de la tragedia española en el Siglo de Oro: la tragedia amorosa, Kassel, Reichenberger, 1997, "Teatro del Siglo de Oro. Estudios de Literatura", vols. 33, 34, 35.

Álvarez Sellers, María Rosa, «"Nada me parece justo / en siendo contra mi gusto": príncipes herederos en el teatro ibérico de los Siglos de Oro», en Del poder y sus críticos en el mundo ibérico del Siglo de Oro, ed. Ignacio Arellano, Antonio Feros y Jesús M. Usunáriz, Madrid/Frankfurt am Main, Iberoamericana/Vervuert, 2013, pp. 25-39.

Álvarez Sellers, María Rosa, «"No hay virtud sin experiencia": pretendientes inesperados y damas al acecho en la tragedia del Siglo de Oro», Abusões (Universidade Estadual do Rio de Janeiro), n. 03, v. 03, ano 02, 2016, pp. 144-187.

Arellano, Ignacio, El escenario cósmico: estudios sobre la comedia de Calderón, Madrid/Frankfurt am Main, Iberoamericana/Vervuert, 2006.

Arellano, Ignacio, «"Lo trágico y lo cómico mezclado": de mezclas y mixturas en el teatro del Siglo de Oro», Rilce, 27.1, 2011, pp. 9-34.

Barone, Lavinia, El gracioso en los dramas de Calderón, New York, IDEA, 2012.

Calderón de la Barca, Pedro, El médico de su honra, ed. Jesús Pérez Magallón, Madrid, Cátedra, 2012.

Calderón de la Barca, Pedro, La cisma de Inglaterra, ed. Francisco Ruiz Ramón, Madrid, Castalia, 1981. 
Calderón de la Barca, Pedro, La vida es sueño, ed. Evangelina Rodríguez Cuadros, Madrid, Espasa-Calpe, 2000.

Calderón de la Barca, Pedro, Los cabellos de Absalón, ed. Evangelina Rodríguez Cuadros, Madrid, Espasa-Calpe, 1989.

Cervantes, Miguel de, La destruición de Numancia, ed. Alfredo Hermenegildo, Madrid, Castalia, 1994.

Greer, Margaret R., «Spanish Golden Age Tragedy: From Cervantes to Calderón», en A Companion to Tragedy, ed. Rebecca Bushnell, Malden (MA), Blackwell, 2005, pp. 351-369.

Hermenegildo, Alfredo, «Hacia una descripción del modelo trágico vigente en la práctica dramática del siglo XVI español», Crítica Hispánica, VII, 1, Spring, 1985, pp. 43-55

Iglesias Feijoo, Luis, «La tragedia nueva y sus problemas. En torno a El médico de su honra de Calderón», en La tragédie espagnole et son contexte européen (XVIeXVIle siècles), ed. Christophe Couderc y Hélène Tropé, Paris, Presses Sorbonne Nouvelle, 2013, pp. 239-248.

Iglesias Feijoo, Luis, «Nueva idea de la tragedia nueva», en En buena compañía. Estudios en honor de Luciano García Lorenzo, ed. Joaquín Álvarez Barrientos, Óscar Cornago Bernal, Abraham Madroñal Durán y Carmen Menéndez-Onrubia, Madrid, CSIC, 2009, pp. 1155-1169.

Lobato, María Luisa, «"Minotauro de Pasife": la mezcla de lo trágico y lo cómico en El castigo sin venganza de Lope y El médico de su honra de Calderón», en La tragédie espagnole et son contexte européen (XVIe-XVIIe siècles), ed. Christophe Couderc y Hélène Tropé, Paris, Presses Sorbonne Nouvelle, 2013, pp. 217-228.

Losada Goya, José Manuel, «Calderón y su honor calidoscópico», en Pedro Calderón de la Barca. El teatro como representación y fusión de las artes, Anthropos, Extra 1, 1997, pp. 65-72.

Maspoch Bueno, Santiago, «Los animales en La vida es sueño», en Pedro Calderón de la Barca. El teatro como representación y fusión de las artes, Anthropos, Extra 1, 1997, pp. 107-111.

Oostendorp, Enrique, «Evaluación de algunas teorías en torno a las tragedias de Calderón», en Las constantes estéticas de la comedia en el Siglo de Oro, Diálogos Hispánicos de Amsterdam, 2, 1981, pp. 65-76.

Oostendorp, Enrique, «La estructura de la tragedia calderoniana», Criticón, 23, 1983, pp. 177-195.

Pedraza Jiménez, Felipe B., «Variedades de la tragedia en el universo de la comedia española», en La tragédie espagnole et son contexte européen (XVIe-XVIle siècles), ed. Christophe Couderc y Hélène Tropé, Paris, Presses Sorbonne NouveIle, 2013, pp. 143-158. 
Ruiz Ramón, Francisco, «El bufón calderoniano y su proyección escénica», en Calderón: sistema dramático y técnicas escénicas. Actas de las XXIII Jornadas de Teatro Clásico, ed. Felipe B. Pedraza Jiménez y Elena E. Marcello, Cuenca, Universidad de Castilla-La Mancha, 2001, pp. 107-124.

Sullivan, Henry W., «Lacan and Calderón: Spanish Classical Drama in the Light of Psychoanalytic Theory», Gestos, 10, 1990, pp. 39-55.

Vega Carpio, Lope de, Arte nuevo de hacer comedias, ed. Felipe B. Pedraza Jiménez y Pedro Conde Parrado, Cuenca, Ediciones de la Universidad de Castilla-La Mancha, 2016.

Vega Carpio, Lope de, El caballero de Olmedo, ed. Francisco Rico, Madrid, Cátedra, 1991.

Vega Carpio, Lope de, El castigo sin venganza, ed. A. David Kossoff, Madrid, Castalia, 1989.

Vitse, Marc, «Calderón trágico», en Pedro Calderón de la Barca. El teatro como representación y fusión de las artes, Anthropos, Extra 1, 1997, pp. 61-64.

Zugasti, Miguel, «A vueltas con el género de La vida es sueño: comedia palatina seria», en La comedia palatina del Siglo de Oro, dir. Miguel Zugasti, ed. Mar Zubieta, Cuadernos de Teatro Clásico, 31, 2015, pp. 257-296. 